\title{
AS ARQUEOLOGIAS DE SÃO BRAZ DO PIAUÍ: \\ APONTAMENTOS INICIAIS SOBRE AS NARRATIVAS E USOS DOS BENS ARQUEOLÓGICOS NO PRESENTE
}

THE ARCHEOLOGIES OF SÃO BRAZ DO PIAUÍ:

INITIAL NOTES ON NARRATIVES AND USES OF ARCHAEOLOGICAL OBJECTS IN THE PRESENT

Leandro Elias Canaan Mageste

Géssika de Sousa Macêdo

Evanilza Lopes de Castro Paes Carlos Eduardo Ferreira dos Santos

Como citar este artigo:

MAGESTE, Leandro E. C. et al. As arqueologias de São Braz do Piauí: apontamentos iniciais sobre as narrativas e usos dos bens arqueológicos no presente. Cadernos do Lepaarq, v. XVII, n.34, p. 164-182, Jul-Dez. 2020. 


\title{
As arqueologias de São Braz do Piauí: apontamentos iniciais sobre as narrativas e usos dos bens arqueológicos no presente ${ }^{\mathrm{a}}$
}

\author{
Leandro Elias Canaan Mageste \\ Géssika de Sousa Macêdo ${ }^{c}$ \\ Evanilza Lopes de Castro Paes ${ }^{\mathrm{d}}$ \\ Carlos Eduardo Ferreira dos Santos ${ }^{\mathrm{e}}$
}

\section{Resumo:}

Nesse artigo, buscaremos refletir sobre os trânsitos dos bens arqueológicos nas paisagens do presente. Nosso interesse com a empreitada será o de explicitar algumas formas de trabalho com esses materiais, olhando atentamente para os seus usos e intepretações nem sempre autorizados. Desse modo, trazemos para discussão alguns contextos do município de São Braz do Piauí, situado no Corredor Ecológico que separa os parques nacionais Serra da Capivara e Serra das Confusões. No local, são frequentes os achados de cerâmicas e líticos, principalmente urnas funerárias, efetuados pela população em suas residências e vias públicas. Por meio de uma arqueologia pública do presente, procuramos acompanhar as narrativas produzidas sobre esses engajamentos, admitindo as possibilidades de se relacionarem com a operacionalização de outras arqueologias.

\section{Palavras-chave:}

Patrimônio arqueológico. Preservação Patrimonial. Multitemporalidade. Arqueologia Pública do Presente. São Braz do Piauí.

\begin{abstract}
:
In this article, we will seek to reflect on the transit of archaeological objects in the social landscapes of the present. Our interest in the project will be to highlight some ways of working with these materials, looking carefully at their uses and interpretations that are not always authorized. Thus, we bring to discussion some contexts of the city of São Braz do Piauí, located in the Corredor Ecológico that separates the national parks Serra da Capivara and Serra das Confusões. On the scene, the findings of ceramics and lithics are frequent, mainly funerary pottery, made by the population in their homes and public roads. Through a public archeology of the present, we seek to follow the narratives produced about these engagements, admitting the possibilities of relating to the operationalization of other archeologies.
\end{abstract}

\section{Keywords:}

Archaeological Heritage. Heritage Preservation. Multitemporality. Public Archaeology of the Present. São Braz do Piauí.

\footnotetext{
a O artigo é fruto das reflexões gestadas no âmbito do projeto "Mapeamento Arqueológico do Município de São Braz do Piauí: Ciência, Tradição e Público", desenvolvido desde 2017, com o apoio do Conselho Nacional de Desenvolvimento Científico e Tecnológico (CNPq) e Pró-reitoria de Pesquisa, Pós Graduação e Inovação da Universidade Federal do Vale do São Francisco (PRPPGI UNIVASF).

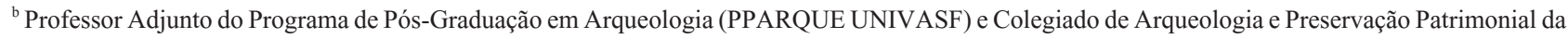
Universidade Federal do Vale do São Francisco (CARQUEOL UNIVASF). Coordenador do Laboratório de Preservação Patrimonial da Universidade Federal do Vale do São Francisco (LAPA UNIVASF). E-mail: leandromageste@gmail.com

${ }^{c}$ Bacharela em Arqueologia e Preservação Patrimonial e mestranda em Arqueologia pela Universidade Federal do Vale do São Francisco (UNIVASF). Colaboradora do Laboratório de Preservação Patrimonial da Universidade Federal do Vale do São Francisco (LAPA-UNIVASF). E-mail: gess.sm23@gmail.com

${ }^{d}$ Graduanda em Arqueologia e Preservação Patrimonial pela Universidade Federal do Vale do São Francisco (UNIVASF). Bolsista de Iniciação Científica do Conselho Nacional de Desenvolvimento Científico e Tecnológico (CNPq). Colaboradora do Laboratório de Preservação Patrimonial da Universidade Federal do Vale do São Francisco (LAPA UNIVASF). E-mail: evanilzalopes@hotmail.com

${ }^{\text {e }}$ Bacharel em Arqueologia e Preservação Patrimonial pela Universidade Federal do Vale do São Francisco (UNIVASF). Colaborador do Laboratório de Preservação Patrimonial da Universidade Federal do Vale do São Francisco (LAPA UNIVASF). E-mail: caducarlos31@hotmail.com
} 


\section{INTRODUÇÃO}

Nesse artigo, buscaremos refletir sobre os trânsitos dos bens arqueológicos nas paisagens sociais do presente. Nosso interesse com a empreitada será o de salientar algumas formas de trabalho com esses materiais, olhando atentamente para os seus usos e intepretações nem sempre autorizados, que se reconfiguram nos territórios da memória e do cotidiano. No exercício, invocaremos para análise os desdobramentos das atividades de pesquisa e extensão realizados no município de São Braz do Piauí, por meio da atuação do Laboratório de Preservação Patrimonial da Universidade Federal do Vale do São Francisco - LAPA UNIVASF.

A cidade está localizada no Sudoeste do Piauí, ocupando um território de 656,367 km², com população estimada de 4.451 habitantes em $2020^{1}$. Assume relevância do ponto de vista arqueológico, situando-se entre os Parques Nacionais Serra da Capivara e Serra das Confusões, em recorte denominado de Corredor Ecológico² (Figura 1), área de preservação ambiental. Historicamente, podemos atribuir as primeiras referências científicas produzidas sobre este contexto às cientistas relacionadas com a Missão Franco-Brasileira a partir da década de 1970 e, posteriormente, Fundação Museu do Homem Americano (FUMDHAM). Capitanearam o devassamento do Sudoeste e Sudeste do Piauí, com foco nos parques e, correlatamente, nas regiões de entorno (MARTIN, 2005). Porém, desde o início do século XX, época de crescimento do povoado, já eram frequentes os relatos a respeito de achados de "potes de barro" no núcleo principal de ocupação, efetuados pela população em suas residências e vias públicas, alguns contendo ossos humanos.

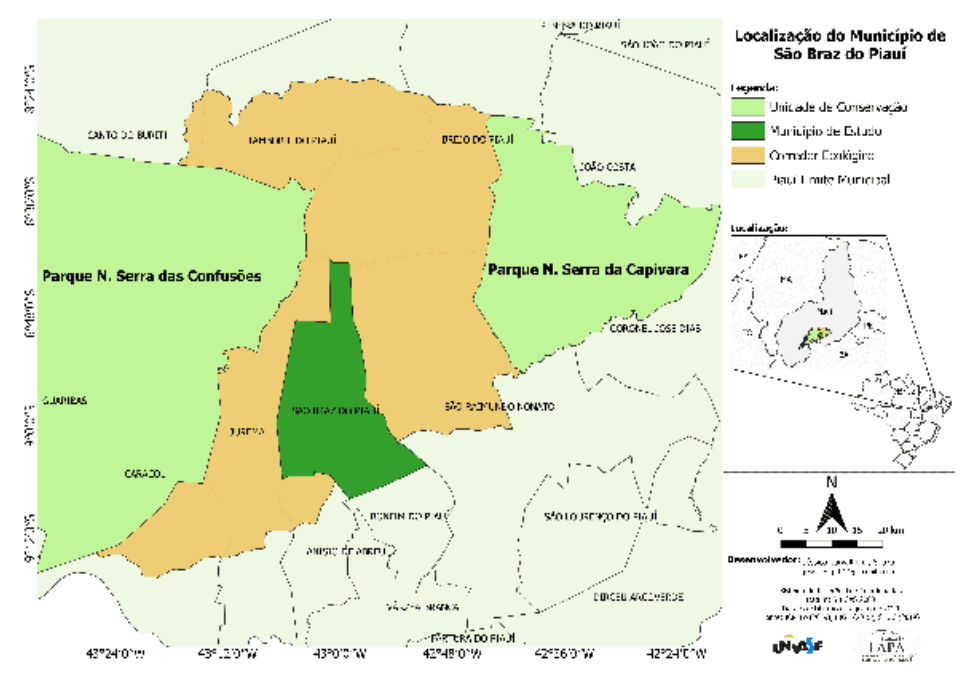

Figura 1 - Localização de São Braz do Piauí. Fonte: ACERVO LAPA UNIVASF

\footnotetext{
1 Projeções do Instituto Brasileiro de Geografia e Estatística (IBGE). Disponível em < https://cidades.ibge.gov.br/ brasil/pi/sao-braz-do-piaui/panorama>, acesso em 20/11/2020.

2 O Parque Nacional da Serra da Capivara foi constituído a partir do Decreto de no 83.548 de 5 de junho de 1979. Atualmente, ocupa uma área de aproximadamente 130.000 hectares. Foi declarado como Patrimônio Cultural da Humanidade pela Organização das Nações Unidas pela Educação, Ciência e Cultura (UNESCO), em 1991. Por sua vez, o Parque Serra das Confusões abrange cerca de 526.108 hectares, sendo criado pelo Decreto s/no de 02.10.98 e Decreto s/n, 30 de dezembro de 2010. Juntas, as áreas de preservação permanente ocupam parte significativa do Sudoeste e Sudeste do Estado, contendo alta densidade de sítios arqueológicos inseridos em diferentes temporalidades e contextos ecológicos. Com o fito de assegurar a preservação e uso sustentável das áreas do entono, foi estipulado em Portaria no 76 de 11 de março de 2005 - Meio Ambiente, o Corredor Ecológico, situado entre os parques, de modo a ocupar uma área de 414.000 hectares, incluindo São Braz do Piauí. Mais informações disponíveis em < https://www.icmbio.gov.br >, acesso em 01/11/2020.
} 
As intervenções mais sistemáticas aconteceram entre 1974 e 1987, quando foram escavados 10 sítios arqueológicos do entorno do Parque Nacional Serra da Capivara (PARNA). Em São Braz do Piauí, as ações abarcaram o salvamento de três urnas funerárias, no centro. A área foi considerada um "extenso sítio a céu aberto" (GUIDON et al, 2007, p.157), delimitado como "sítio São Braz". Posteriormente, esse pacote arqueológico volumoso foi abordado de forma pontual em diferentes investigações, que se concentraram preferencialmente nos domínios pré-coloniais, com problematização de sítios de enterramentos e padrões de grafismos rupestres, além de caracterizações de cerâmica e lítico, com datações que se distribuem de 10.000 anos BP até o limite de $880 \pm 50$ BP (GUIDON et al, 2009). De acordo com as informações expressas nas bases virtuais do Cadastro Nacional de Sítios Arqueológicos (CNSA - IPHAN) em $2020^{3}$, o município apresenta atualmente um total de 68 manifestações registradas junto ao IPHAN, entre sítios e ocorrências de variadas tipologias.

No decorrer dos anos, a frequência de descobertas gerou apelos às instituições científicas situadas na região por parte de alguns moradores, para execução de atividades de pesquisa com foco nos bens supostamente ameaçados (Figura 2 e 3). Tal arranjo contribuiu não somente para a salvaguarda dos dados científicos referentes aos contextos pré-coloniais da região, mas também para o estabelecimento de vínculos entre pesquisadoras (es), instituições e as pessoas envolvidas nos achados. A presença constante dos especialistas fomentou curiosidade a respeito dos trabalhos, estimulando a busca por especialização em algumas situações (MACÊDO, 2019). Não por acaso, no papel de docente e discentes da UNIVASF, temos acompanhado e nos reconhecido no ingresso de jovens com biografias individuais marcadas por algum tipo de envolvimento com práticas arqueológicas: observaram ou participaram de escavações arqueológicas em quintais; conversaram com as (os) arqueólogas (os) que passavam nas escolas e nas ruas do município e que falavam de patrimônio arqueológico e do PARNA. Foi exatamente sob essas circunstâncias que as provocações que alimentaram as incursões em São Braz do Piauí ganharam contornos mais sólidos, culminando na proposição de um programa de arqueologia pública do presente, implementado em 2017 e ainda em vigência.
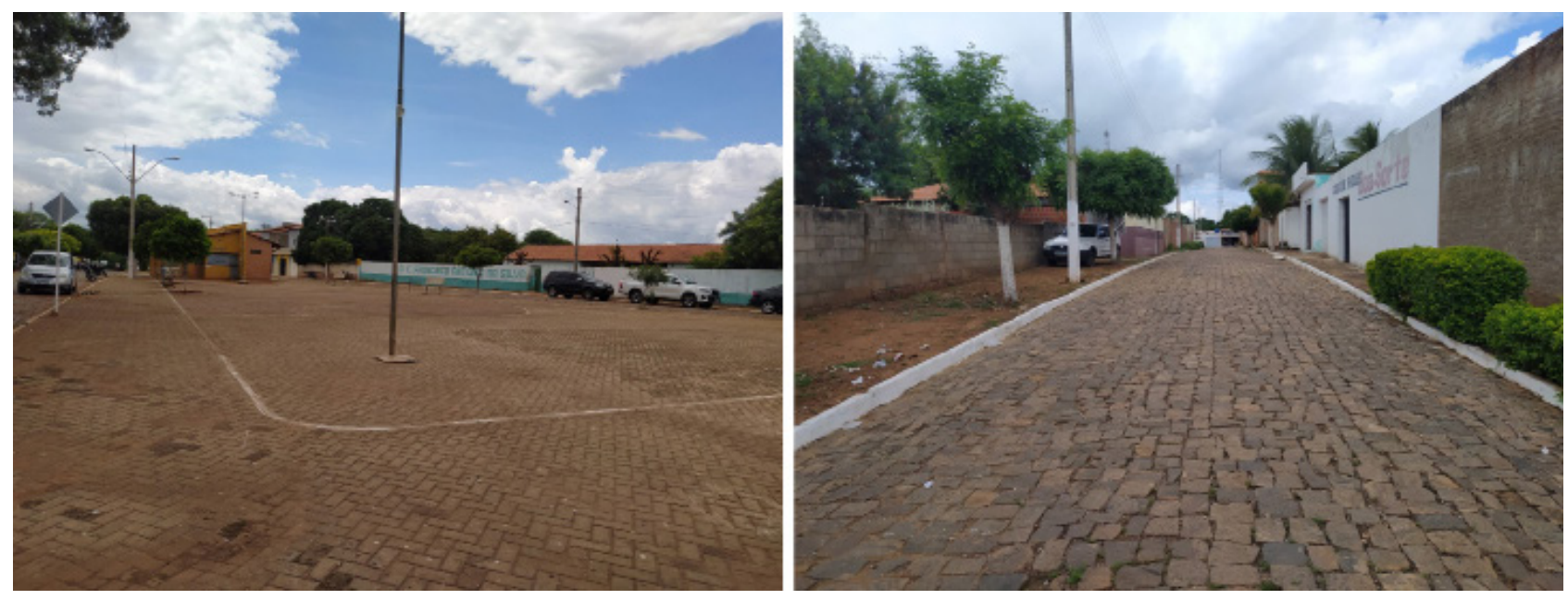

Figura 2 - Sítios arqueológicos de São Braz do Piauí nas paisagens do presente. Fonte: Acervo LAPA UNIVASF

Disponível em < http://portal.iphan.gov.br/sgpa/?consulta=cnsa>, acesso em 01/11/2020. 


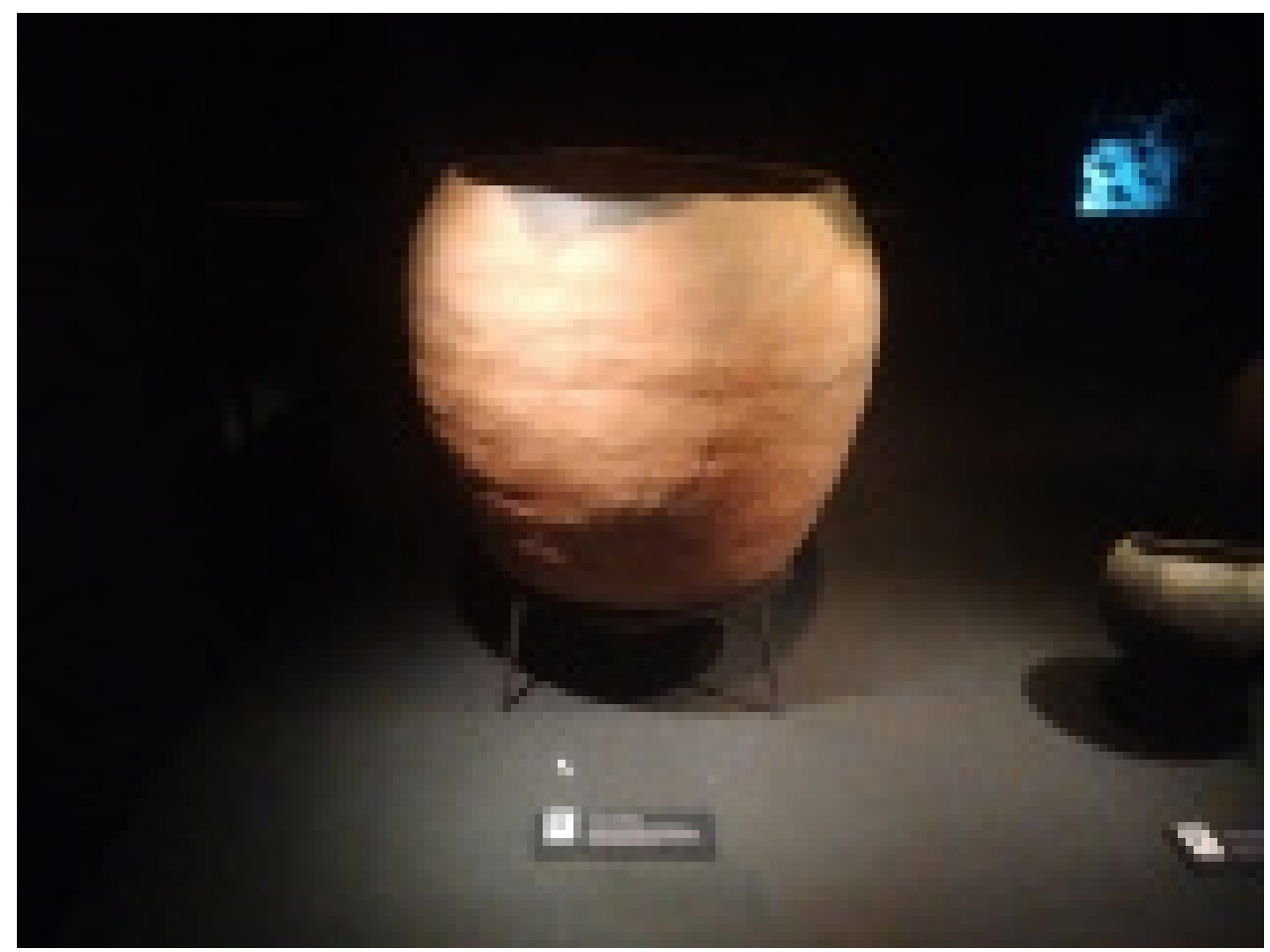

Figura 3 - Urna funerária de São Braz do Piauí, exposto no Museu do Homem Americano, em São Raimundo Nonato. Fonte: MACÊDO, 2019

\section{ARQUEOLOGIA PÚBLICA DO PRESENTE: INTERFACES TEÓRICAS E METODOLÓGICAS}

Na execução da pesquisa, defendemos o desenvolvimento de uma arqueologia pública do presente, construída a partir de uma intercessão de abordagens teóricas e metodológicas. Com o termo, tentamos expressar uma perspectiva em estado constante de formação, que se reconfigura a partir dos interesses emergentes do trabalho colaborativo. O primeiro passo nessa tarefa foi nos afastar de perspectivas multiculturalistas, centradas na ideia de multivocalidade e relativização científica. Não nos pareceu prudente abandonar a posição de pesquisadores, já que era justamente esse conhecimento especializado aquele demandado nas manifestações de alguns moradores, quando contactavam alguma instituição científica local ou buscavam formação na área (cf. CABRAL, 2014). Concordamos com as críticas recentes efetuadas por González-Ruibal (2016), ao denunciar as armadilhas do populismo epistêmico, que se tornaram hegemônicos nos debates sobre patrimônio. Como estratégia, seguimos um caminho mais próximo de outros arqueólogos latino-americanos, rechaçando um positivismo empírico reacionário, pautado em explicações objetivas do mundo, para combinar elementos científicos com a explicitação de aspectos sociopolíticos referentes aos seus processos de produção (BENAVIDES, 2011).

Particularmente, nos aproximamos da abordagem simétrica proposta por Cabral (2014), em seu estudo junto com o Wajãpi, ao entender a arqueologia como uma forma de conhecimento do mundo, expressa na construção de narrativas que conectam vestígios materiais com diferentes temporalidades. Nessas condições, a realização de trabalhos colaborativos pode vir a constituir um cenário propício para a comunicação entre sistemas de conhecimento distintos, produzidos no 
contexto de experiências e lógicas de mundo específicas. Ao contrário das posições defendidas pelo multiculturalismo, a incursão não visa a produção de consensos, mas se movimentar entre saberes, produzindo pontes, comparações e traduções que explicitem formas variadas de arqueologia. Não falamos de multivocalidade, mas sim de interculturalidade. No caso, foi a provocação necessária para pensar nos usos dos bens arqueológicos em São Braz do Piauí, como evidências para pensar sobre o funcionamento de arqueologias que não dependem das categorias de "patrimônio" ou "pesquisador" para existirem.

Para dar conta dessas diferentes dimensões de significados e entender melhor as conexões entre os vestígios materiais e outros coletivos, recorremos as provocações de Bezerra (2017), ao reivindicar uma arqueologia atenta para a memória e o afeto. Em seus estudos junto a comunidades da Amazônia, a pesquisadora percebeu que "as pessoas sempre demonstravam algum tipo de relação com as coisas do passado, ainda que fosse uma "não relação"” (BEZERRA, 2017, p.12). Inseridos no cotidiano, dessas comunidades, o que priorizamos como patrimônio arqueológico é observado, descrito e interpretado, podendo ser colecionado, reutilizado, destruído ou mesmo ignorado. Essas práticas são consequências da atuação de outras temporalidades, consistindo em formas de engajamento com a arqueologia que estão quase sempre na clandestinidade. Ao contrário do discurso geralmente presente nas políticas preservacionistas, de que o patrimônio local não é valorizado, os contextos dinâmicos contemporâneos apontam para a "complexidade e a potência dessas outras epistemologias sobre a cultura material arqueológica” (BEZERRA, 2017, p.13). Na empreitada, reside o reconhecimento de que o envolvimento com as ideias de presente e passado acontecem a partir de intervenções materiais e discursivas que são efetuadas em múltiplas contemporaneidades (HARRISON, 2019). Ao nosso ver, para encarar essas questões, existe necessidade de composição de uma arqueologia do presente, atenta para a multitemporalidade, que não esteja necessariamente focada em fornecer analogias sobre o passado ou tratar pessoas como simples informantes (GONZÁLEZ-RUIBAL, 2012). São preocupações consonantes com definições vigentes de arqueologia pública em realidade latino-americanas, principalmente aquelas dedicadas em revisar as maneiras como conhecimentos e evidências materiais são apropriados fora do campo acadêmico.

Na América Latina, a arqueologia pública pode constituir um desdobramento da arqueologia social. A confluência demarca iniciativas abertas para a construção de práticas arqueológicas por meio da educação e envolvimento comunitário, problematizando perspectivas liberais, nacionais e autoritárias sobre patrimônio, assim como a persistência de relações coloniais na sua manipulação (RICHARDSON \& ALMANSA-SÁNCHEZ, 2015). Essas sobreposições, de acordo com Benavides (2011), costumam ser conduzidas por arqueólogos que se visualizam conectados ao passado que estão interpretando, sem respeitar divisões clássicas pelos quais as disciplinas estabelecem seus recortes de análise. Enxergam-se como um "produto final desse processo histórico", não para reforçar particularismos identitários, mas para assumir que o "passado está diretamente relacionado a quem somos como povo, e esse conhecimento é necessário para a construção histórica do presente e futuro (....)"(BENAVIDES, 2011, p.174). Em São Braz do Piauí, o fluxo de moradores interessados que buscaram treinamento formal em arqueologia com o propósito de estudar sua região e produzir uma 
narrativa científica nos seus termos, coaduna-se com esta premissa, demarcando um uso político da ciência na criação de novos problemas temáticos (SANTOS, 2020).

As preocupações teóricas que relatamos mostraram-se compatíveis com o estabelecimento de um cenário de pesquisa-ação, que firmasse uma base metodológica por onde pudéssemos organizar estratégias colaborativas. De modo geral, refere-se à ação e resolução de um problema coletivo, no qual os envolvidos participam de forma cooperativa ou participativa de sua resolução (THIOLLENT, 1986). Para fins de contextualização, trata-se de metodologia ressignificada na América Latina a partir da década de 1960, apresentando-se consonante com os esforços de tornar o processo de produção de conhecimento mais democrático e comprometido politicamente. No Brasil, aparece relacionada com o pensamento de Paulo Freire, considerando o responsável pela formatação de um estilo participativo de pesquisa, entendida enquanto ação educativa transformadora e intercultural. Implica desse modo, a compreensão de que existem diferenças e tensões nos encontros estabelecidos, mas também chances de dialogicidade e eticidade (PERUZZO, 2016). De maneira transversal, a etnografia arqueológica amparou nossas incursões, ao se integrar com o método etnográfico nas observações sobre os recortes dinâmicos de interação (HAMILAKIS, 2011). Em termos práticos, conduzimos entrevistas estruturadas e semiestruturadas, oficinas de expressão tecnológica, rodas de conversa, exposições, diagnóstico e prospecção arqueológica participativos, levantamentos patrimoniais colaborativos, registro de locais de memória, empreendimentos pontuais e sistemáticos de educação patrimonial. Por questões de espaço, não entraremos em detalhes a respeito de todas essas ações, que vem sendo sistematizadas e refletidas pelos envolvidos no projeto.

Certamente, as metodologias adotadas foram catalisadas no desdobramento de relações afetivas. Explicando melhor, alguns quadros só se mostraram acessíveis para a aplicação de uma abordagem colaborativa por que eram conduzidos em parte por moradores da região, especializados academicamente ou interessados em arqueologia. Afinal, nem todos se sentem à vontade para narrar para desconhecidos ocasionais as suas impressões sobre o patrimônio arqueológico ou mesmo os usos que conferem a ele. No caso de São Braz do Piauí, os autores anônimos de descobertas arqueológicas são amigos, vizinhos, familiares e colegas da equipe, que disponibilizaram e autorizaram a publicação de suas histórias a partir do reconhecimento de uma experiência comum relacionada com a vida na mesma comunidade. No caso do primeiro autor desse texto, até então externo a esta realidade, esse reconhecimento não significou a aceitação de uma posição confortável de mediador, expectador passivo ou narrador onisciente das ações que se desdobraram. De forma parecida com Favret-Saada (2005), aceitou ser afetado para além dos limites seguros da observação participante, ocupando uma posição de ação no intuito de fomentar novas possibilidades de comunicação, nem sempre verbal ou intencional, mas fundamentalmente afetivas e politicamente orientadas.

\section{ARQUEOLOGIA (S) DE SÃO BRAZ DO PIAUÍ}

No final de 2016, aconteceu a descoberta de urnas cerâmicas no perímetro urbano de São Braz do Piauí, durante a construção de uma cisterna em residência particular, colocando assuntos 
relacionados com a arqueologia na ordem do dia (MACÊDO, 2019). Ao tomarem conhecimento, os discentes de Arqueologia e Preservação Patrimonial oriundos do município acionaram a UNIVASF, o que culminou na aplicação da disciplina de Métodos Arqueológicos para a condução do resgate (FREITAS, 2018). Aproveitamos a oportunidade de acesso para começar a seguir os materiais e suas associações (cf. INGOLD, 2012). Persistimos ainda por estas trilhas, sem perspectiva de retirada.

\section{A CIDADE DENTRO DO SÍTIO ARQUEOLÓGICO: ALGUNS ENQUADRAMENTOS}

Neste percurso, averiguamos que os materiais que tinham sido recentemente resgatados foram encontrados por Topazio ${ }^{4}$, de 25 anos. Na ocasião, prestava serviços de auxiliar de construção civil durante a abertura de uma cisterna na residência de Dona Esmeralda, no centro da cidade. Dias depois, encontrou outro "pote de índio", dessa vez durante a construção de um edifício vizinho. Interessado, acompanhou os trabalhos de salvamento, testemunhando sua repercussão: diz que os moradores paravam para ir conferir os objetos e dar uma olhada nas intervenções, sendo comum perguntarem: "será que tem ouro aí?". Lembra-se que "a primeira urna ainda estava inteira, já a segunda urna estava quebrada. Na primeira foi encontrada o corpo de uma criança, já na segunda foi encontrada parte de uma mandíbula" ${ }^{5}$. O detalhamento das informações reflete-se no interesse de Topázio pelos objetos, que o levou a visitar o Museu do Homem Americano, em São Raimundo Nonato. Afirma que algumas urnas expostas ali são na realidade de São Braz do Piauí. Deveriam, por isso, ficar na cidade. A noção de valor aparece qualificada pelas repercussões do trabalho realizado pela FUMDHAM na região, associada a figura da Doutora Niede Guidón (MACÊDO, 2019).

São opiniões parecidas com aquelas expressas por Berilo, de 40 anos. Atualmente, possui uma distribuidora de cervejas, sendo conhecido pelos estudantes locais por se envolver na organização de movimentos culturais. Berílio se assume como técnico em arqueologia, com larga experiência em serviços de prospecção e escavação arqueológica, tendo atuado com a FUMDHAM em sítios da Serra da Capivara e Serra da Confusões. Participou também de programa de arqueologia preventiva referente a transposição do rio São Francisco. Interessado no assunto desde criança, foi o autor de diversos achados na região. Garante "sentir" a existência de sítios arqueológicos, fortalecendo desse modo suas habilidades. Sempre entra em contato com a FUMDHAM quando localiza algum objeto. Contudo, diz que isso não é um hábito generalizado: "Geralmente, as urnas são descartadas, o material lítico é guardado e vendido. Quando aparecem em alguma obra, as urnas são descartadas junto com o entulho da própria construção"6.

\footnotetext{
$4 \quad$ No momento, optamos pela utilização de pseudônimos, de acordo com vontade dos participantes. Diversas vezes nos foram relatados temores em relação a repercussão de suas opiniões e descobertas, considerando a atuação frequente de instituições normatizadoras na região, como o IPHAN, a FUMDHAM e a própria UNIVASF.

5 Entrevistas realizadas em 01 de maio de 2017. Registro escrito disponível nos Arquivos de Campo do Laboratório de Preservação Patrimonial da UNIVASF.

$6 \quad$ Entrevistas realizadas em 03 de abril de 2019. Registro escrito disponível nos Arquivos de Campo do Laboratório de Preservação Patrimonial da UNIVASF.
} 
Práticas de destruição são bem comuns, de acordo com Dona Esmeralda, de 61 anos, a proprietária da obra onde Topázio achou uma urna. Meses após o salvamento arqueológico dos materiais, estava bastante chateada com as repercussões que o "pote" gerou. Para ela, foi desconfortável ter uma equipe de profissionais em sua casa, uma "invasão de privacidade". Além de ter atrasado a sua obra em cerca de dois dias, atraíram "pessoas estranhas", que ao passar em frente à residência, entravam sem cerimônias para observar a escavação dos arqueólogos. Ela mesma não acompanhou, pois estava ocupada em seu mercadinho. Por conta de todo esse transtorno, tem certeza que "quem chegar a encontrar mais potes, vão (sic) jogar fora também. As pessoas não querem mais construir. E se construir e encontrar, ninguém avisa mais não" 7. Dona Esmeralda conhece esses materiais desde a infância. Quando tomava conhecimento ou experimentava uma descoberta do tipo, escutava falar que foram deixados pelos "índios" que moravam ali a muito tempo atrás. Justamente por conta dessa recorrência, afirmou que muitos desses "potes" foram descartados logo quando irrompiam pelo solo, recordando-se de diversas construções que se valeram desse procedimento (MACÊDO, 2019).

As percepções contrastam com as dos irmãos Euclásio e Rubi, respectivamente com 47 e 39 anos, que encontraram quatro urnas no quintal da casa de sua família, no início da década de 2000. Eles residem no local até hoje. Euclásio foi o responsável pelo achado. Aconteceu na sua adolescência, durante a abertura de uma cisterna com o seu pai, já falecido. Deparou-se com uma urna, acompanhada por uma machadinha polida e cerâmica. Acionou profissionais da FUMDHAM, que realizaram a escavação sob a supervisão dos moradores da casa. Criança na época, Rubi relembra da delicadeza das escavações, que capturou as suas atenções. Conta que "[arqueólogos] geralmente, vinham em três carros e com todo o equipamento e ferramentas que iriam precisar para o trabalho, inclusive água e comida"8. De acordo com ela, "só pediam o espaço e silêncio, porque eles gostavam de trabalhar em silêncio. Quando era no final do dia, eles só apareciam para dizer que tinham terminado e para mostrar o que tinham encontrado" ${ }^{\prime}$. Nesses encontros, Rubi obtinha informações sobre os vestígios, saciando algumas curiosidades. Sempre escutava que dentro desses potes poderia existir ouro. Relembra que: "Perguntei se tinha ouro dentro, ele me disse [arqueólogo]: ouro não tem não, mas tem um tesouro aqui"10. Atualmente, o quintal serve para uma diversidade de funções: depósito de ferramentas e utensílios domésticos, lixo, espaço de trânsito para os moradores da propriedade e também espaço de brincadeiras para as crianças. Os pontos de localização das urnas são rememorados a cada visita, associadas com os aspectos evidentes da residência: o alicerce, a cisterna e o muro. Para além dessas marcações, as urnas existem como uma possiblidade concreta de materialização. De acordo com Euclásio, “nesse quintal, onde cavar acha pote. Quando o pessoal está

\footnotetext{
$7 \quad$ Entrevistas realizadas em 01 maio de 2017. Registro escrito disponível nos Arquivos de Campo do Laboratório de Preservação Patrimonial da UNIVASF.

$8 \quad$ Entrevista realizada em 01 de maio de 2017. Registro escrito disponível nos Arquivos de Campo do Laboratório de Preservação Patrimonial da UNIVASF.

$9 \quad$ Entrevista realizada em 01 de maio de 2017. Registro escrito disponível nos Arquivos de Campo do Laboratório de Preservação Patrimonial da UNIVASF.

10 Entrevista realizada em 01 de maio de 2017. Registro escrito disponível nos Arquivos de Campo do Laboratório de Preservação Patrimonial da UNIVASF.
}

MAGESTE, Leandro E. C. et al. As arqueologias de São Braz do Piaui: apontamentos iniciais sobre as narrativas e usos dos bens arqueológicos no presente. Cadernos do Lepaarq, v. XVII, n.34, p. 164-182, Jul-Dez. 2020. 
construindo aqui, eu já aviso: tem um tesouro ai ${ }^{\prime \prime 11}$. Atribuiu esse reconhecimento às suas vivências pessoais, marcada por envolvimento com as descobertas e contato com as (os) pesquisadoras (es) na região. Essa opinião não é consensual como fez questão de frisar. Euclásio diz ter conhecimento de diversas urnas evidenciadas pela população, que foram imediatamente descartadas para resolver um transtorno: evitar paralisações em obras e sanar temores de assédios sobre o terreno por parte dos especialistas. O objeto então é quebrado, para ver "se tem ouro dentro" e depois jogado fora, nos entulhos da própria construção. Euclásio optou pela doação, "pois, sei que tem mais gente que se interessa, se ficar aqui não vai me servir de nada"12, diz ele.

O tratamento conferido as urnas não é o mesmo dispensado aos artefatos líticos. Rubi nos contou que após as escavações no quintal, sempre pensava a respeito de uma das machadinhas evidenciadas, que parecia estar coberta por algum tipo de metal derretido. Nunca soube exatamente o porquê. Chegou inclusive a buscar informações sobre a peça junto a FUMDHAM, quando não foi mais localizada. Algum tempo depois, encontrou um objeto similar, que é cuidadosamente guardado no armário da cozinha. A atração pela estética, juntamente com a percepção de refinamento técnico, amalgama-se com experiências afetivas para esta seleção. Por sua vez, Euclásio chegou a ter uma coleção particular de machadinhas polidas no passado, formadas a partir de coletas fortuitas, sendo depois doada. Os objetos o faziam lembrar de seu pai, que gostava muito desses assuntos. As lembranças desse acervo vêm balizadas por certo tom de descontentamento com a doação: Euclásio gostaria de saber a respeito do paradeiro desses materiais, porém, nunca obteve notícias. Sabe somente que os profissionais que o contactaram não se vinculavam com a FUMDHAM, o que dificultou sua busca por maiores informações (MACÊDO, 2019).

Ao nos afastarmos do centro de atuação mais sistemática das (os) arqueólogas (os), conhecemos Dona Cristal, 89 anos, que vinha observando nossas andanças pela cidade a algum tempo. A senhora reside próxima à escola municipal, em casa situada bem em frente a uma figueira. Trata-se um marcador importante, como ela fez questão de frisar: sob a árvore existe uma "urna" relacionada com os "índios" da região. De acordo com ela, moravam ali, no lugar onde estava a sua casa. Quando criança, recorda-se que ainda habitavam as terras de São Braz do Piauí, entrando em contato ocasionalmente com os moradores do povoado que se aventuravam pelas serras. Esta chance de interação não está restrita ao passado, podendo se manifestar no presente sob condições apropriadas: "é só cantar que eles vêm", nos disse ao mencionar os efeitos provocados por certas canções utilizadas para invocá-los. Os materiais também parecem constituir um dos catalisadores para esses eventos. Recorda-se que certa noite, um moço conhecido teria estacionado o seu carro debaixo da figueira e pernoitado. No dia seguinte, levantou-se assustado, reclamando que escutou assovios a noite inteira. Nesse ponto, Dona Cristal nos confidenciou, sorrindo: "eram eles"13.

\footnotetext{
11 Entrevista realizada em 01 de maio de 2017. Registro escrito disponível nos Arquivos de Campo do Laboratório de Preservação Patrimonial da UNIVASF.

12 Entrevista realizada em 01 de maio de 2017. Registro escrito disponível nos Arquivos de Campo do Laboratório de Preservação Patrimonial da UNIVASF.

13 Entrevista realizada em 04 de março de 2020. Registro escrito e em áudio disponível nos Arquivos de Campo do Laboratório de Preservação Patrimonial da UNIVASF.
}

MAGESTE, Leandro E. C. et al. As arqueologias de São Braz do Piaui: apontamentos iniciais sobre as narrativas e usos dos bens arqueológicos no presente. Cadernos do Lepaarq, v. XVII, n.34, p. 164-182, Jul-Dez. 2020. 
Às vezes, o próprio surgimento do material já constitui uma manifestação sobrenatural, que intervém diretamente sobre problemas pessoais, conforme aprendemos com a Sra. Ametista, de 72 anos e atualmente residente do distrito de Lagoa de Cima. Na infância, morou no centro de São Braz do Piauí, acompanhando de perto diversos achados de "potes de barro" e "coriscos". Sabe que foram produzidas pelos antigos "caboclos" da região. Poderiam cair também com os raios, interferindo em determinadas contendas. Contou que quando sua irmã ficou grávida, sofreu com desconfianças do marido acerca da paternidade. $O$ homem pediu para que "um raio caísse em cima dele se $o$ filho fosse dele"14. Certo dia, durante a formação de uma tempestade, quase foi atingido enquanto ajeitava as telhas da casa. A descarga elétrica "não o atingiu, mas caiu em cima de um pote de água da cozinha e cavou o chão. Quando foram ver, tinha uma pedra de corisco no lugar que o raio caiu”'15.

O aparecimento de uma machadinha foi um evento decisivo na história de vida de Citrino, de 24 anos - na época, estudante de arqueologia. Desde criança, sempre foi muito curioso em relação a movimentação de arqueólogas (os) no centro da cidade. Observava atentamente as escavações e os materiais. Certa noite, na sua infância, lembra-se de ter sonhado que caminhava próximo a igreja católica no centro, encontrando uma machadinha nos fundos do edifício. No dia seguinte, ao realizar uma inspeção no local, achou o objeto. A descoberta foi um estimulo para especializar-se em arqueologia. Hoje, já formado, tem interesse particular pela análise dos machados polidos dos sítios da cidade e de contextos arqueológicos relacionados com o passado recente.

Passado e presente, materialidade e invisibilidade aparecem nesses recortes amalgamados, sem necessidade de distinção ou como assuntos encerrados. Sob essas premissas, percebemos não somente a formulação de declaração de sentidos, mas inclusive a condução de estratégias metodológicas para lidar com os materiais e suas associações afetivas. Pudemos avançar mais por essas reflexões nos nossos encontros com o casal Jaspe e Ágata, respectivamente com 81 e 84 anos. Hoje, residem em ponto mais distante do centro, mas no passado moraram em casa que também foi palco de salvamento arqueológico. O sr. Jaspe se reconhece como neto de um "índio" da região. Recorda-se das histórias que ouvia do seu avô: antigamente, São Braz do Piauí eram ocupado por dois grupos, localizados em pontos opostos nas serras que circundam o município. Na área central, enterravam os mortos em "potes de barro" e montavam "acampamentos". Os grupos mantiveram convivência pacífica entre si, que foram rompidas por motivos desconhecidos. De todo modo, "foram se afastando"16, com a chegada de outras pessoas.

De acordo com a sra. Ágata, o avô de seu marido portava diversas pontas de flechas, além de saber encantamentos, expressos em canções, que intermediariam as relações com "esses caboclos". Sabe recitá-los até hoje. Além disso, lembra-se exatamente dos pontos onde os "índios" acampavam e de onde instalavam suas aldeias, apontando na paisagem. Essas experiências culminam em

\footnotetext{
$14 \quad$ Entrevista realizada em 03 de abril de 2019. Registro escrito disponível nos Arquivos de Campo do Laboratório de Preservação Patrimonial da UNIVASF.

15 Entrevista realizada em 03 de abril de 2019. Registro escrito disponível nos Arquivos de Campo do Laboratório de Preservação Patrimonial da UNIVASF.

16 Entrevista realizada em 04 de abril de 2019. Registro escrito e em áudio disponível nos Arquivos de Campo do Laboratório de Preservação Patrimonial da UNIVASF.
} 
saberes específicos para tratar das materialidades: localizam exatamente os pontos de existência de urnas funerárias. Esses locais são marcados por uma "coroa de pedras" (Figura 4), deixada pelos "caboclos"17. Consiste em um conjunto de fragmentos de rochas variadas, dispostos de maneira concêntrica, que geralmente irrompem pelo solo na época das chuvas. Por isso, é possível prever com certa confiança os locais onde estão enterrados.
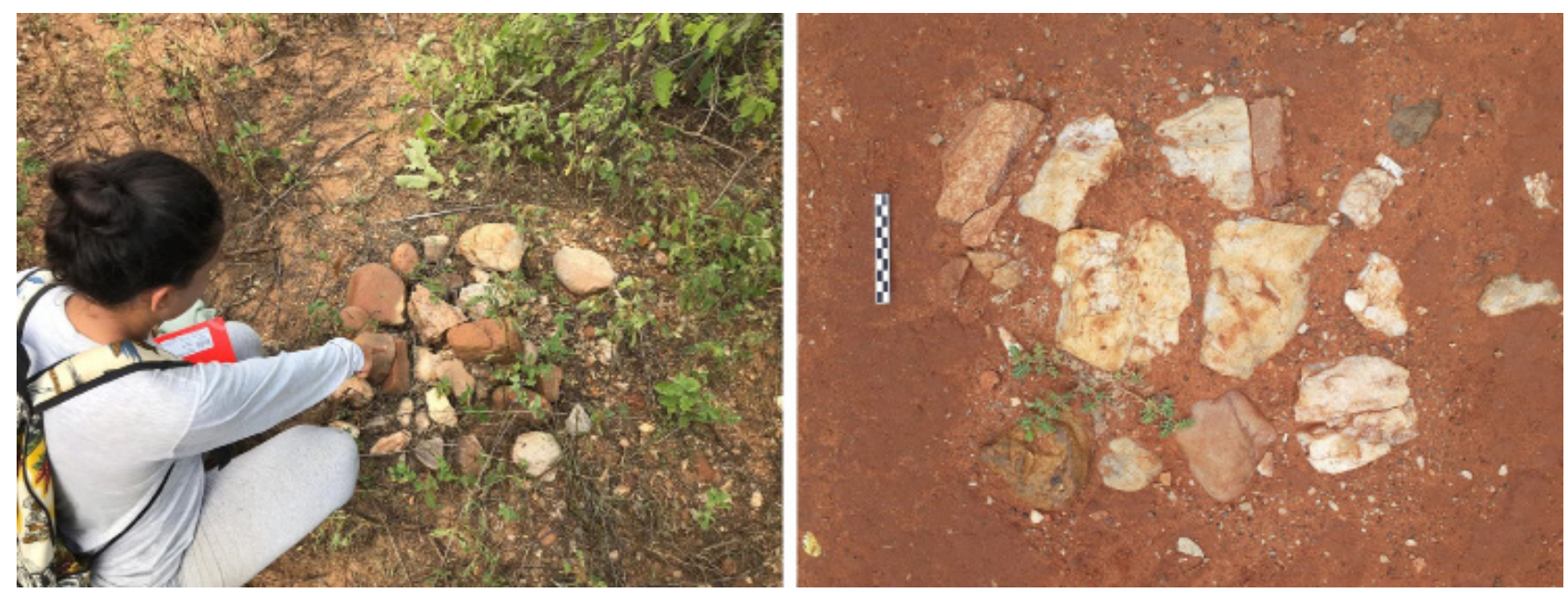

Figura 4 - Coroa de pedras. Fonte: Acervo LAPA UNIVASF

Em todas as situações relatadas, não aparecem dúvidas em relação a autoria e função das peças: foram produzidos pelos "índios" / "caboclos" que habitavam a região e que atuavam como "machados", "coriscos" "urnas" e "potes de barro". Pudemos adicionar complexidade ao assunto ao conhecer o Sr. Olivin, de 83 anos, radialista e atuante nos movimentos políticos da cidade. Contou que antes da chegada das (os) pesquisadoras (es), não se costumava empregar o termo "cemitério indígena" para falar dos achados. De acordo com ele, "nome cemitério foi dada pela Niède Guidon. Antes não se falava em cemitério, nem sabiam que era de índio"18. Como consequência, "índios" e "caboclos" podem figurar nas narrativas como termos que não exigem separação. Diferentes formas de conhecimento esbarram-se no tratamento desses materiais: um conhecimento determinado pela experiência pessoal e expectativas coletivas; e aquele construídos nos quadros de intervenção arqueológica e ação dos seus participantes. Essa articulação não parecia constituir em contradição, mas simplesmente na possibilidade de existência de múltiplos significados em uma mesma dimensão: a do nosso encontro.

\section{OS USOS DOS BENS ARQUEOLÓGICOS NO PRESENTE}

Ao nos movimentarmos por São Braz do Piauí, percebemos que é impossível sair de dentro do sítio arqueológico. Geralmente, os fragmentos cerâmicos de poucas dimensões ficam dispersos

\footnotetext{
17 Entrevista realizada em 04 de abril de 2019. Registro escrito e em áudio disponível nos Arquivos de Campo do Laboratório de Preservação Patrimonial da UNIVASF.

18 Entrevista realizada em 03 de abril de 2019. Registro escrito disponível nos Arquivos de Campo do Laboratório de Preservação Patrimonial da UNIVASF.
}

MAGESTE, Leandro E. C. et al. As arqueologias de São Braz do Piaui: apontamentos iniciais sobre as narrativas e usos dos bens arqueológicos no presente. Cadernos do Lepaarq, v. XVII, n.34, p. 164-182, Jul-Dez. 2020. 
pela superfície, não despertando maiores atenções enquanto sofrem com processos naturais de degradação (Figura 5). Na verdade, se misturam com os restos de vasilhames utilizados pelos próprios moradores no passado. Desse modo, para a maioria das pessoas, os cacos inseridos nesse contexto são vistos simplesmente como os restos dos potes usados antigamente (Figura 6). Para as lascas líticas, o tratamento conferido é semelhante, pois acabam encaradas como parte integrante de uma paisagem com diversos afloramentos de quartzo. De modo geral, ambos costumam ser reconhecidos como bens arqueológicos de um passado mais remoto por aqueles com algum envolvimento mais efetivo com práticas formais de arqueologia: os estudantes do município e participantes e observadores das intervenções arqueológicas.
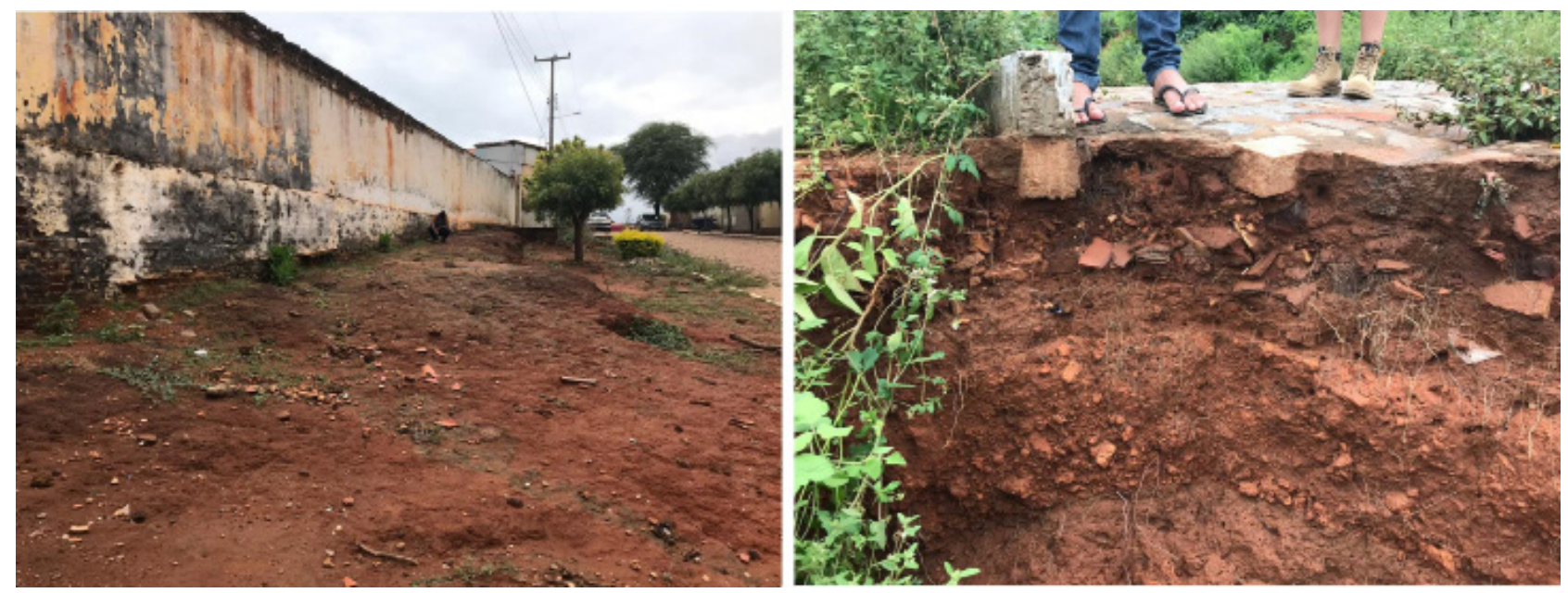

Figura 5 - Fragmentos cerâmicos expostos em superfície. Fonte: Acervo LAPA UNIVASF

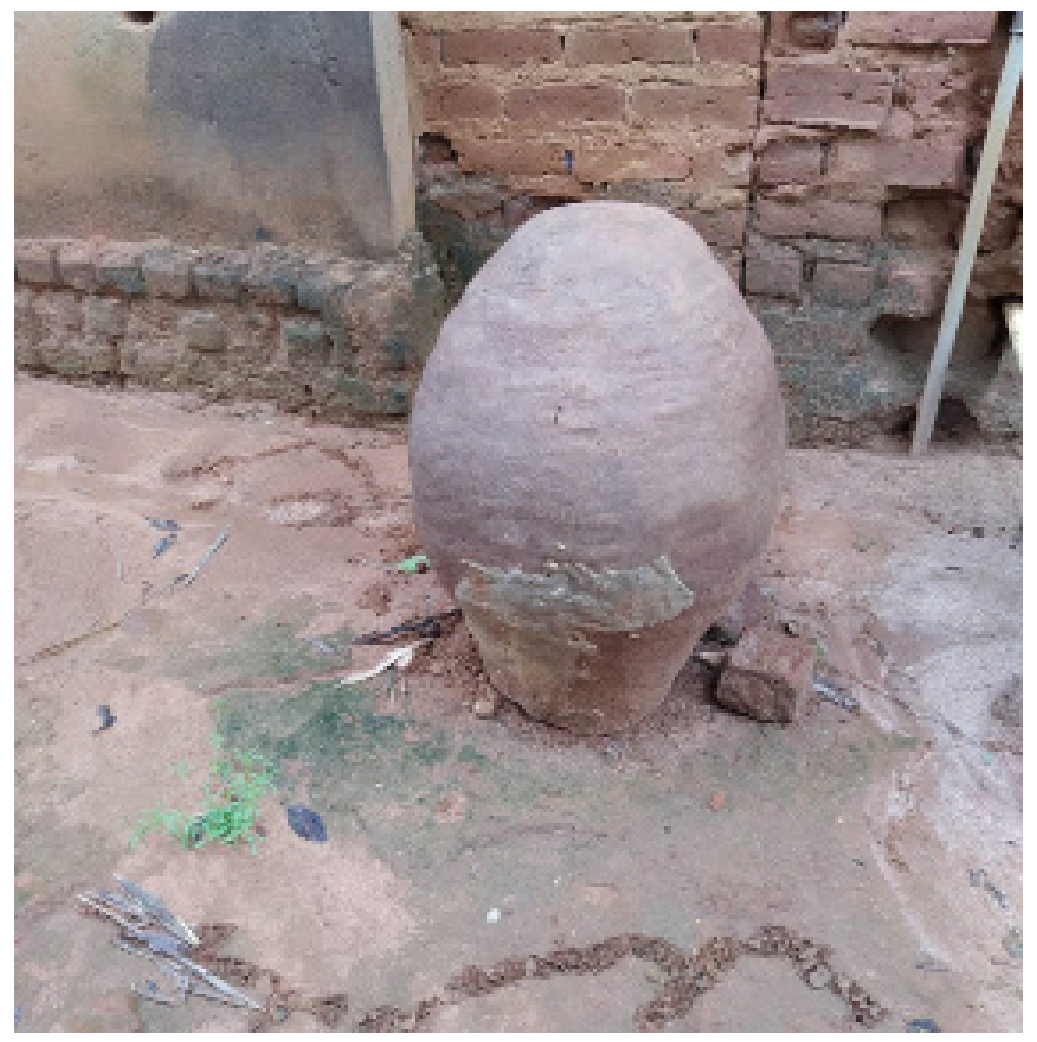

Figura 6 - Pote de barro contemporâneo, utilizado para o armazenamento de água. Fonte: Acervo LAPA UNIVASF 
Quando as atenções incidem sobre as urnas funerárias totalmente e parcialmente inteiras, bem como as machadinhas, outro rumo é tomado. São esses achados que geralmente mobilizam as instituições regionais, a partir das notícias da descoberta. Em tais ocasiões, o material é resgatado por uma equipe de pesquisadoras (es) e, geralmente, são levados para a reserva técnica da FUMDHAM. Alguns dos vestígios arqueológicos encontrados em situações desse tipo, estão expostos no Museu do Homem Americano, a exemplo das urnas funerárias, porém vinculadas ao contexto do Parque Nacional Serra da Capivara, sem referência ao município (PEREIRA, 2019).

Conforme as conversas indicavam, tratava-se de uma face muito restrita do tratamento conferido aos bens arqueológicos no presente, que incluíam um arsenal de práticas que não seguem as expectativas dos discursos de preservação patrimonial. São circunstâncias onde as agências dos materiais são potencializadas, constituindo uma nova trama de significados que complexificam as estratégias de proteção e/ou destruição porventura empregadas. Sobre as urnas, catalisam uma marcação de diferença mais explicita, que é operacionalizada por meio de tomadas de posições distintas quando o encontro com ela acontece. Podem provocar suspeitas de que escondem um tesouro enterrado, incentivando algumas pessoas, nunca identificadas, a quebrarem potes inteiros na esperança de enriquecer. Para aqueles particularmente desconfiados ou desinteressados dos propósitos das (os) pesquisadoras (es), livrar-se das urnas de maneira discreta é vista como uma resolução rápida para apaziguar inseguranças com a propriedade de suas terras, além de manter resguardado seus espaços íntimos.

Por sua vez, instrumentos líticos, como como machadinhas, batedores, percutores e pontas de flechas, podem ter sua capacidade de ação amplificadas, quando se manifestam como o "corisco". 0 quadro invoca as conclusões de Miller (2013) para fenômenos paranormais em casas mal assombradas, onde o sobrenatural emerge em situações de estranheza que são provocadas por uma qualidade dos objetos, que é a sua agência. De acordo com Olivier (2011), é justamente essa estranheza que confere o tom misterioso que experimentamos na presença de "coisas arqueológicas". A habilidade de provocar "assombro" permanece retraída na materialidade, persistindo para além dos esquemas analíticos e interpretativos que criamos para domesticá-la. Talvez por isso, no caso dos instrumentos líticos de São Braz do Piauí, apresentam-se também como objetos de poder, responsáveis por atrair sorte ou azar, dependendo das relações e expectativas constituídas no momento em que se apresentam.

Esses artefatos transmutam-se em objetos afetivos, podendo ser colecionados por motivos variados e retirados de circulação (Figura 7). Colecionar consiste em uma forma de organização de conhecimento e comunicação com o mundo. Envolve afetividade, na medida em que incorre de uma cisão, que separa objetos de um determinado cenário, para torná-lo familiar, inserido em temporalidades transitórias, como os ciclos da vida (LOPES, 2010). São peças que lembram da vida de antes, ativando memórias sobre parentes e amigos já falecidos e relacionados de alguma maneira com o achado. Chamam a atenção pela sua beleza e caráter exótico, expressa pelas formas, pela cor, textura e técnicas que capturam os olhares. Entre aqueles que se envolveram mais diretamente com as intervenções arqueológicas na região, apesar de referências às explicações científicas serem 
ativadas com mais frequência, seus efeitos são sempre negociados na dimensão da experiência, que culminam em escolhas de doação e colecionismo. O reconhecimento de que os artefatos são na verdade um "tesouro", produzido por "índios" e passível de ser investigado por profissionais especializados, não constitui obstáculos para o manejo dessas referenciais no presente e sim mais uma de suas qualidades.
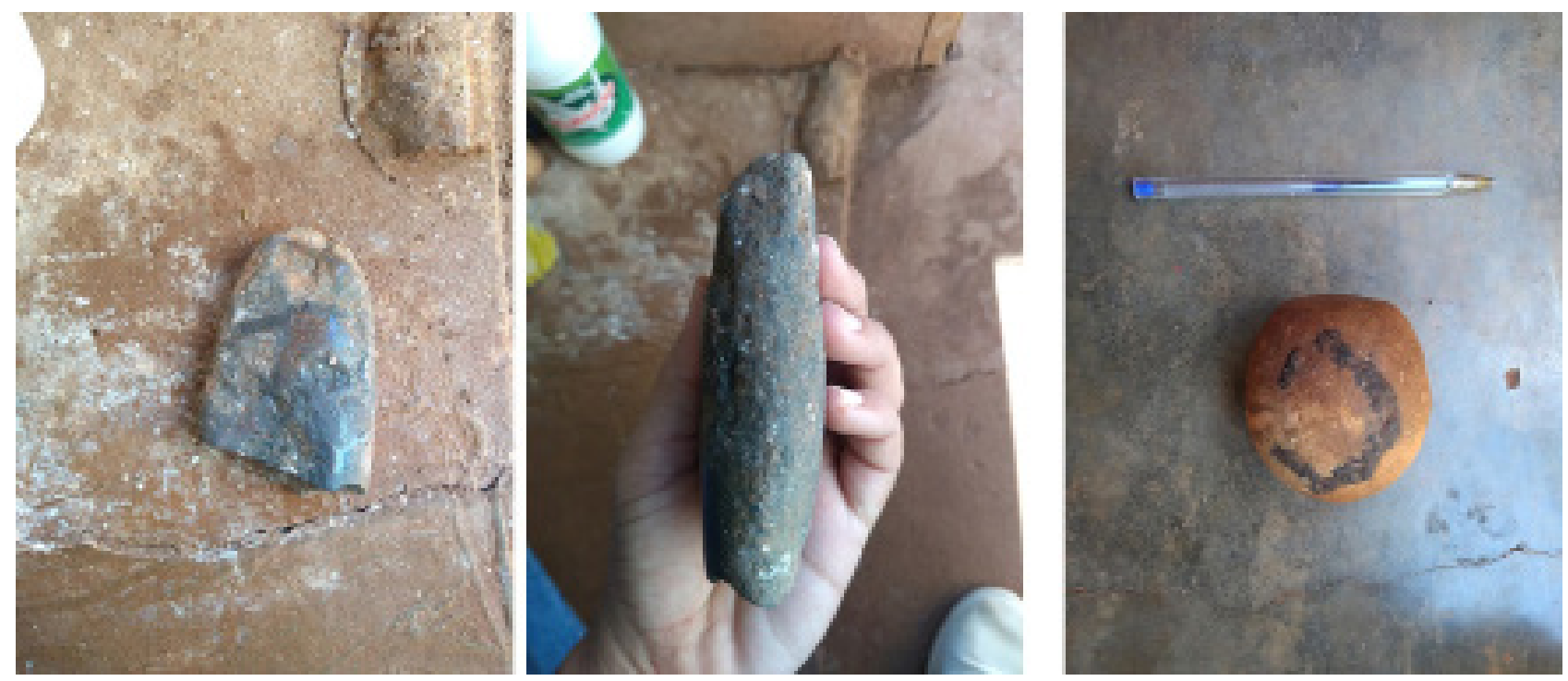

Figura 7 - Instrumentos líticos colecionados como objetos afetivos em São Braz do Piauí. Fonte: Acervo LAPA UNIVASF

Finalmente, os instrumentos líticos podem ser reutilizados em outras funções no presente. Em campo, cruzamos com as histórias de vida desses objetos por acaso: ao percorremos a cidade e visitar alguns colaboradores, costumávamos encontrar machadinhas no interior de suas residências, sendo utilizado como aparador de portas, principalmente no banheiro. Verificamos também a utilização de um pilão, para macerar alho. Inseridos em uma outra trama de relações, os artefatos continuavam a participar da formação de espaços domésticos, confundindo divisões de "objetos do passado" e "objetos do presente". Raramente falamos sobre eles: em nossos encontros, permaneciam invisíveis, nunca sendo invocados nas conversas ou mesmo associados aos "coriscos" ou "machadinhas". Longe dos olhares especializados, eram simplesmente pilão ou aparador de portas. Esse aparente silêncio não representa uma situação de apatia ou mesmo submissão, muito pelo contrário. Por desfrutarem de uma atenção periférica, estão livres para participarem discretamente de molduras por onde sujeitos e objetos constituem-se dialeticamente (MILLER, 2013).

\section{CONSIDERAÇÕES FINAIS}

Ao final desses apontamentos, consideramos que refletir sobre a inserção da (s) arqueologia (s) no presente, sustenta-se no reconhecimento de que as narrativas relacionadas com os objetos arqueológicos são mais complexas, envolvendo uma diversidade de relações que constituem os cenários por onde essas evidências são utilizadas e interpretadas (MACHADO, 2017). Com 
essa constatação, não queremos dizer que a confluência entre coisas e pessoas; comunidades, pesquisadoras (es) e instituições; ou entre passado e presente acontecem de forma pacífica, em direção ao acordo multicultural. As contradições desses relacionamentos não são normalizadas, existindo na forma de possibilidades que predominam em circunstâncias específicas, mas nem sempre excludentes. Por isso, os objetos apresentam-se como "potes de barro" e "urnas funerárias", "corisco" e "machado de índio", "coisas do passado", "de antigamente", mas que age também de maneiras diversificadas no presente. Materiais são descartados, doados, colecionados, reutilizados, temidos, investigados, preservados ou simplesmente ignorados.

A natureza particular de tais engajamentos encontra respaldo na configuração histórica de São Braz do Piauí, nas formas de reelaboração do passado por meio da memória social, na construção do imaginário sobre as populações indígenas. Ressoa também com a inserção da região em um programa de pesquisas sistemáticas e depois na área de expansão do ensino superior público. As reflexões que trouxemos no momento são resultados dos nossos esforços de entrever algumas dessas articulações, reconhecendo a necessidade de nos aprofundarmos em algumas problemáticas. Para a continuidade, mostra-se promissora a análise de intercessões de raça, classe e gênero na operação com os bens arqueológicos. A construção de um imaginário sobre a morte deve ser também levada em conta com mais afinco, na medida que a existência de um "cemitério indígena" as vezes gera desconforto, provocando temores em relação aos objetos dos mortos, como as urnas funerárias. Finalmente, torna-se necessário explorar os processos de musealização do patrimônio arqueológico evidenciado na região, desde a atuação da FUMDHAM até o IPHAN e UNIVASF, no intuito de refletir sobre os enquadramentos elaborados para os achados em contexto institucional e seus impactos na produção de narrativas sobre a memória indígena e a arqueologia.

De todo modo, nos arranjos que apresentamos existem margens para diferentes associações, que são sempre negociadas na perspectiva das experiências e que culminam em uma diversidade de arqueologias, se considerarmos o termo condizente com as formas dos materiais ativarem múltiplas temporalidades simultaneamente (HAMILAKIS, 2011). Em uma perspectiva transversal, acompanhar esses fluxos permite refletir a respeito dos efeitos políticos relacionados com a transformação desses bens em patrimônio arqueológico. Na América Latina, conforme alerta Gnecco (2009), em decorrência da herança colonial, o desenvolvimento de arqueologia científica contribuiu para o rompimento de vínculos entre memória indígenas e os objetos agrupados como "registro arqueológico", por meio da exclusão de suas conexões com outros vieses ontológicos e epistemológicos. Isto permitiu a consolidação de discursos condizentes com a formatação de uma história nacional, que celebra populações indígenas exterminadas no passado, ao passo que invisibiliza sua existência quando ela se torna um problema muito próximo no tempo. Para essa arqueologia, o valor dos vestígios emerge de sua qualidade imanente de testemunha de ocupação de um tempo remoto, já encerrado, que passa a ser perturbado no momento em que é descoberto.

Frente este cenário, para o Sudoeste e Sudeste do Piauí, podemos considerar que as incursões arqueológicas realizados desde a década de 1970, conferiram visibilidade para temática indígena, fornecendo as primeiras evidências para a construção de uma história de longa duração, que 
justificasse iniciativas preservacionistas. A longo prazo, foi esta atuação que assegurou a instalação de instituições científicas e de ensino, potencialmente revolucionárias ao democratizar e incentivar a ampliação de estudos. Ao mesmo tempo, por conta dos objetos perseguidos com as investigações, os dados gerados podem ter contribuído para o fortalecimento de discursos históricos que admitiam a presença dessas populações somente em um passado mais remoto, até serem completamente exterminadas no final do século XVIII e XIX (ASSIS, 2016).

Porém, persistem notícias sobre encontros com indígenas em períodos bem mais recentes, estendendo-se pelas primeiras décadas do século XX e acessadas por meio da memória dos moradores mais antigos e expressas em narrativas materiais multitemporais. Apesar de serem denominados por termos coloniais genéricos e pejorativos, tais como "tapuias" e "caboclos", as classificações podem ser reformuladas, para se referir justamente a um horizonte mais próximo e familiar. Os incômodos com esse descompasso, além de repercutirem nas formas como os bens arqueológicos são manejados, interpretados e comunicados, têm servido de provocação para o estabelecimento de novas questões de pesquisa, organizadas a partir de um conjunto de evidências até então marginais ou invisíveis, evidenciados por moradores cientificamente engajados (SANTOS, 2012; SANTOS, 2019; MACÊDO, 2019; SANTOS, 2020).

Finalmente, o reconhecimento dos vieses autoritários que acompanham a gênese da arqueologia em realidades configuradas historicamente pela colonização, como é o caso do Brasil, não se traduz em uma apologia para uma destruição "socialmente justificada", mas na exigência da interculturalidade no seu planejamento, com articulação de diferentes saberes sob as lentes das afetividades, que permitem a proposição e ressignificação não só do patrimônio arqueológico, mas da própria disciplina. Em uma conjuntura neoliberal marcada por negacionismo histórico, pósverdade e ataques organizados as humanidades, tal postura pode contribuir para o fortalecimento de práticas de pesquisa e de trabalho com o patrimônio arqueológico, ao explicitar os seus processos de construção, sua diversidade de significados, bem como os seus propósitos políticos. 


\section{REFERÊNCIAS BIBLIOGRÁFICAS}

ASSIS, Rafael da Silva. Os índios do Território Serra da Capivara: história, memória e ensino. Dissertação (Mestrado profissional em Ensino de História). Universidade Federal do Tocantins, Araguaína, 2016.

BENAVIDES, Hugo O. Retornando à origem: arqueologia social como filosofia latino-americana. Tradução de Sérgio Almeida Loiola, Maria Lemke e Alecsandro José P. Ratts. Revista Terceiro Incluído: Transdisciplinaridade \& Educação Ambiental, Goiânia, v.1, n. 2, p. 164194, 2011.

BEZERRA, Marcia. Teto e Afeto: sobre as pessoas, as coisas e a arqueologia na Amazônia. $1^{\circ}$ edição. Belém: GK Noronha, 2017

CABRAL, Mariana Petry. No tempo das pedras moles: arqueologia e simetria na floresta. Tese (Doutorado em Antropologia). Universidade Federal do Pará, Belém, 2014.

FAVRET-SAADA, Jeanne. Ser afetado. Tradução de Paula de Siqueira Lopes. Cadernos de Campo, n. 13, p. 155-161, 2005.

FREITAS, Aline Reinaldo. Práticas funerárias dos grupos ceramistas do Município de São Braz do Piauí. Monografia (Trabalho de Conclusão de Curso em Arqueologia e Preservação Patrimonial). Universidade Federal do Vale do São Francisco, São Raimundo Nonato, 2018.

GONZÁLEZ RUIBAL, Alfredo. Hacia otra arqueología: diez propuestas. Complutum, v. 23, n.2, p. 103116, 2012.

GONZÁLEZ-RUIBAL, Alfredo; GONZÁLEZ, Pablo Alonso; CRIADO-BOADO, Felipe. Against reactionary populism: Towards a new public archaeology. Antiquity, v.92, p. 507-515 \& 525-27, 2018.

GNECCO, Cristobal. Caminos de la Arqueología: de la violencia epistémica a la relacionalidad. Bol. do Museu Paraense Emílio Goeldi. Ciências Humanas, v. 4, n.1, p.15-26, 2009.

GUIDON, Niede; FELICE, Gisele Daltrine; LIMA, Carlos Fabiano Marques. Salvamento arqueológico na área da Adutora do Garrincho. Revista FUMDHAMENTOS, v.1, n.6, São Raimundo Nonato, p. 126-16, 2007.

GUIDON, Niede; PESSIS, Anne-Marie; MARTIN, Gabriela. Pesquisas arqueológicas na região do Parque Nacional Serra da Capivara e seu entorno (Piauí - 1998 - 2008). Revista FUMDHAMENTOS, n.8, p. 2-61, 2009.

HAMILAKIS, Yannis. Archaeological Ethnography: A Multitemporal Meeting Ground for Archaeology and Anthropology. Annual Review of Anthropology, n. 40, p. 399-414, 2011.

INGOLD, Tim. Trazendo as coisas de volta à vida: emaranhados criativos num mundo de materiais. Horizontes Antropológicos, Porto Alegre, ano 18, n. 37, p. 25-44, jan./jun. 2012.

LOPES, José Rogério. Colecionismo e ciclos de vida: uma análise sobre percepção, duração e transitoriedade dos ciclos vitais. Horizontes Antropológicos, Porto Alegre, ano 16, n. 34, p. 377-404, jul./dez. 2010

MACÊDO, Géssika de Sousa. "Aqui, onde cavar acha pote": Patrimônio Arqueológico nos quintais 
dos moradores de São Braz do Piauí e seus usos e significados no presente. Monografia (Trabalho de Conclusão de Curso em Arqueologia e Preservação Patrimonial). Universidade Federal do Vale do São Francisco, São Raimundo Nonato, 2019.

MACHADO, Juliana Salles. Arqueologias indígenas, os Laklãnõ Xokleng e os objetos do pensar. Revista de Arqueologia, v. 30, n. 1, p. 89-119, 2017

MARTIN, Gabriela. Pré-história do Nordeste do Brasil. 4 edição. Recife: Editora Universitária da UFPE, 2005.

MILLER, Daniel. Trecos, troços e coisas: estudos antropológicos sobre a cultura material. Tradução de Renato Aguiar. $1^{\circ}$ edição. Rio de Janeiro: Editora Zahar, 2013.

OLIVIER, Laurent. The Dark Abyss of Time: Archaeology and Memory. $1^{\circ}$ ed. Lanham, MD: AltaMira Press, 2011.

PEREIRA, Larissa Campos. Ferramentas da memória: musealização da arqueologia em São Raimundo Nonato - PI. Monografia (Trabalho de Conclusão de Curso em Arqueologia e Preservação Patrimonial). Universidade Federal do Vale do São Francisco, São Raimundo Nonato, 2019.

PERUZZO, Cicilia M. Krohling. Epistemologia e método da pesquisa-ação. Uma aproximação aos movimentos sociais e à comunicação. In: XXV Encontro Anual da Compós, na Universidade Federal de Goiás, Goiânia, de 7 a 10 de junho de 2016. Disponível em <http://www.compos.org.br/biblioteca/epistemologiaem\%C3\%A9tododape squisa-a\%C3\%A7\%C3\%A3o...ciciliaperuzzo.modelocompos2016._3270.pdf.>. Acessado em 15/08/2020. RICHARDSON, Lorna-Jane; ALMANSA-SÁNCHEZ, Jaime. Do you even know what public archaeology is? Trends, theory, practice, ethics. World Archaeology, v. 47, n.2, p. 194-211, 2015.

SANTOS, Raimundo Maurício da Costa. A ocupação dos grupos humanos pré-históricos no sítio arqueológico de São Braz, no município de São Braz do Piauí. Monografia (Trabalho de Conclusão de Curso em História). Universidade Estadual do Piauí, São Raimundo Nonato, 2012.

SANTOS, Pablo Patrick Jovino. Memórias e Narrativas sobre as Populações Indígenas em São Raimundo Nonato - Pl e Microrregião: Uma descrição sobre as produções históricas antecedentes, abordagens precursoras e relatos orais. Monografia (Trabalho de Conclusão de Curso em Arqueologia e Preservação Patrimonial). Universidade Federal do Vale do São Francisco, São Raimundo Nonato, 2019.

SANTOS, Carlos Eduardo Ferreira. História Oral e Cultura Material: O Engenho de Cana-de-açucar do Sr. Abílio Ferreira no município de São Braz do Piauí. Monografia (Trabalho de Conclusão de Curso em Arqueologia e Preservação Patrimonial). Universidade Federal do Vale do São Francisco, São Raimundo Nonato, 2020.

THIOLLENT, Michel. Metodologia da pesquisa-ação. $2^{\circ}$ edição. São Paulo: Cortez, 1986. 